\section{Comments on two subdermal implant articles: author's response}

Diana Mansour ${ }^{1}$ makes eight points about the articles in the October 2010 issue of the Journal on subdermal implants. $^{23}$ I will respond to each of them in turn.

1. It is correct that Leiras (the pharmaceutical division of Huhtamäki Oy) manufactured Norplant ${ }^{\circledR}$. With some pharmaceutical products the manufacturer is the same as the marketing authorisation holder and with some it is not. At the time of design of the cascade training programme prior to launch and at launch of Norplant in 1993, the marketing authorisation holder was Roussel Laboratories. The company subsequently became Hoechst Roussel and later Hoechst Marion Roussel. Mergers and takeovers are routine in the pharmaceutical industry. Regarding the timing of the demise of Norplant in the UK, Hoechst Marion Roussel withdrew Norplant from the market in April 1999. Implanon ${ }^{\circledR}$ was not launched until September 1999.

2. It is correct that the instructions for Norplantinsertion did not mention the biceps/triceps groove. Nevertheless, there was no attempt to direct clinicians to avoid the groove.

3. Organon's own information to professionals about Implanon's new insertion site, dated July 2008 , states that "this change was made in order to minimise the risk of neurovascular damage in the event of an incorrectly placed deep implant. The previous reference to bicipital groove has been removed as the neurovascular bundle lies just deep to the groove". Interpretation of the directions about the new site may vary. If you aim proximally along the arm parallel to the humerus, you are posterior to the groove. If, on the other hand, you aim for the shoulder tip you may end up over the biceps. My preference is to identify the groove and then keep away from it. I personally have followed Fraser's advice since 2006, using an insertion site $1 \mathrm{~cm}$ anterior to the biceps/triceps groove; experienced clinicians go either anterior or posterior to the groove. ${ }^{4}$

4. I obviously cannot argue with Dr Mansour's own experience of selfremoval. But this is anecdotal; there are no case reports in the scientific literature. I disagree that the two reports she cites are evidence in favour of malicious intentional self-removal. The report by Jaffer and Whalen was at 5 months after insertion, supposedly in response to side effects. ${ }^{5}$ 
The report by Gwinnell was billed as an expulsion, but was an implant 6 months after insertion with evidence of a local infection and the proximal end of the implant very superficial; the implant was removed by a clinician. ${ }^{6}$ Mansour's criticism of my legal paper in its failure to discuss selfremoval seems inappropriate in light of the lack of evidence of this kind of scenario. I have not seen any cases of suspected self-removal in my clinical practice or cases where the evidence supported self-removal in my legal practice. In my role as an expert witness I have seen eight cases of absent implant with clear evidence in favour of non-insertion of Implanon, in one of which for example the claimant was awarded $£ 15000$ in damages. To me, this emphasis on possible selfremoval is misleading. The thrust of this section of my article was that non-insertion, while rare, has been a real problem with Implanon. The existence of non-insertion is acknowledged by the Faculty of Sexual and Reproductive Healthcare. ${ }^{7}$ The article with my co-authors emphasised that training is not the whole answer in prevention. The MHRA have stated that they worked closely with MSD in the development of Nexplanon in response to spontaneous adverse incident reporting. ${ }^{8}$ Hopefully the advent of Nexplanon will result in the elimination of non-insertion; only time will tell.

5. The suggestion that all women are asked to confirm the presence of the implant in their arm by palpation, as well as by the clinician doing this, is not my idea. In fact it has been recommended by Mansour and her colleagues $^{9}$ among others. It is also recommended to the user in the Patient Information Leaflet for both Implanon and Nexplanon.

6. Mansour is even more cautious than my recommendation about sending women with difficult to palpate implants to regional centres; I can only commend the caution, but it may be unrealistic not to allow more experienced local clinicians to remove partially palpable implants.

7. Mansour makes a good point about retention of an impalpable implant in a woman with a subsequent desire to become pregnant. I acknowledge that there may be circumstances in which the risk of extensive dissection down onto an implant may be chosen by women who want to conceive.

8. My sentence on migration worded "it is not thought that a rod can migrate significantly in the arm unless it is placed subcutaneously" could perhaps be modified by adding the words "or deeper" at the end.
Sam Rowlands, MD, FFSRH

Institute of Clinical Education, Warwick Medical

School, Coventry, UK; sam.rowlands@warwick.ac.uk

\section{Competing interests None.}

J Fam Plann Reprod Health Care 2011;37:120-121. doi:10.1136/ffprhc.2011.0045

\section{REFERENCES}

1 Mansour D. Comments on two subdermal implant articles [Letter]. J Fam Plann Reprod Health Care 2011;37:119-120.

2 Rowlands S, Sujan MA, Cooke M. A risk management approach to the design of contraceptive implants. J Fam Plann Reprod Health Care 2010:36:191-195.

3 Rowlands S. Legal aspects of contraceptive implants. J Fam Plann Reprod Health Care 2010;36:243-248.

4 Fraser IS. The challenges of location and removal of Implanon ${ }^{\circledR}$ contraceptive implants. J Fam Plann Reprod Health Care 2006;32:151-152.

5 Jaffer K, Whalen S. Self removal of Implanon ${ }^{\circledR}$. a case report. J Fam Plann Reprod Health Care 2005;31:248.

6 Gwinnell E. Expulsion of Implanon ${ }^{\circledR}$. J Fam Plann Reprod Health Care 2007:33:211.

7 Faculty of Sexual \& Reproductive Healthcare. Faculty Statement on Use of Contraceptive Implants. 2011. http://www.fsrh.org/admin/uploads/ FacultyStatementImplantsJan2011.pdf [accessed 4 January 2011].

8 Macdonald V. Implanon Contraception Failures Cost NHS $£ 200,000$. 2011. http://www. channel4.com/news/implanon-contraceptionfailures-cost-nhs-200-000 [accessed 4 January 2011].

9 Singh M, Mansour D, Richardson D. Location and removal of non-palpable Implanon ${ }^{\circledast}$ implants with the aid of ultrasound guidance. J Fam Plann Reprod Health Care 2006;32:153-156 